\title{
Radical Carbon-Carbon Bond Formations Enabled by Visible Light Active Photocatalysts
}

\author{
Carl-Johan Wallentin, John D. Nguyen, and Corey R. J. Stephenson*
}

\begin{abstract}
This mini-review highlights the Stephenson group's contribution to the field of photoredox catalysis with emphasis on carbon-carbon bond formation. The realization of photoredox mediated reductive dehalogenation initiated investigations toward both intra- and intermolecular coupling reactions. These reactions commenced via visible light-mediated reduction of activated halogens to give carbon-centered radicals that were subsequently involved in carbon-carbon bond forming transformations. The developed protocols using Ru and Ir based polypyridyl complexes as photoredox catalysts were further tuned to efficiently catalyze overall redox neutral atom transfer radical addition reactions. Most recently, a simplistic flow reactor technique has been utilized to affect a broad scope of photocatalytic transformations with significant enhancement in reaction efficiency.
\end{abstract}

Keywords: Carbon-carbon bond · Flow reactor · Photocatalysis · Radical · Visible light

\section{Introduction}

Over the last century, organic photochemistry has been developed into a powerful synthetic tool that has proven very effective in the construction of molecular complexity, especially for the formation of small- and medium-sized heterocyclic and carbocyclic compounds. ${ }^{[1]}$ Despite the remarkable advances of photochemistry, the necessity of using high-energy light (UV light) remains a shortcoming. Special equipment such as light sources and reactors are needed to efficiently and safely conduct reactions, which are costly for laboratories that do not routinely employ photochemical transformations. More importantly, high-energy light has the ability to excite multiple functionalities, which consequently limits the functional group compatibility. In the late 1970's, Kellogg and coworkers introduced low-energy visible light-mediated single electron transfer (SET) processes catalyzed by dyes, such as $\left[\mathrm{Ru}(\mathrm{bpy})_{3}\right]^{2+}$, and managed to combine typical radical reactivity with mild photocatalytic conditions in formal hydride reductions of various substrates. ${ }^{[2]}$ Even though a few more examples emerged at the time, ${ }^{[3]}$ the synthetic community did not realize the potential of visible light-mediated redox catalysis until recently. In par-

${ }^{\star}$ Correspondence: Prof. C. R. J. Stephenson Department of Chemistry

Boston University

590 Commonwealth Ave

Boston, MA 02215, USA

Tel.: 1-617-358-5089

Fax: 1-617-353-6466

E-mail: crjsteph@bu.edu ticular, the MacMillan group, ${ }^{[4]}$ the Yoon group, ${ }^{[5]}$ and the Stephenson group ${ }^{[6]}$ have advanced the field of visible light-facilitated radical transformations. Common characteristics of these recent developments include high yields, mild conditions, high functional group tolerance, and low catalyst loadings. In addition, the development of photoredox catalysis exemplifies the principles of green chemistry by eliminating the use of hazardous radical initiators and environmentally harmful reagents. ${ }^{[7]}$ In this mini-review, the specific developments from the Stephenson laboratory are highlighted with an emphasis on photocatalytic generation of carbon-centered radicals with subsequent carbon-carbon bond formation (Fig. 1).

\section{Reductive and Oxidative Quenching}

The most commonly employed photocatalysts are Ir- and Ru-based polypyridyl complexes that absorb visible light and undergo excitation to a long-lived excited state $\left({ }^{3} \mathrm{MLCT}\right){ }^{[8]}\left[\mathrm{Ru}(\mathrm{bpy})_{3}\right]^{2+}$ is perhaps the most widely known and utilized photocatalyst because it is easy to synthesize, and it possesses suitable redox properties in both the ground state and the excited state (Fig. 1). The ability of this photocatalyst to serve both as a strong reductant $(\mathrm{Ru}(\mathrm{III}) / * \mathrm{Ru}(\mathrm{II})=-0.87 \mathrm{~V} \text { vs } \mathrm{SCE})^{[9]}$ and a strong oxidant $(* \mathrm{Ru}(\mathrm{II}) / \mathrm{Ru}(\mathrm{I})=+0.78$ $\mathrm{V}$ vs SCE ${ }^{[9]}$ from the excited state allows for diverse applications toward reaction de-

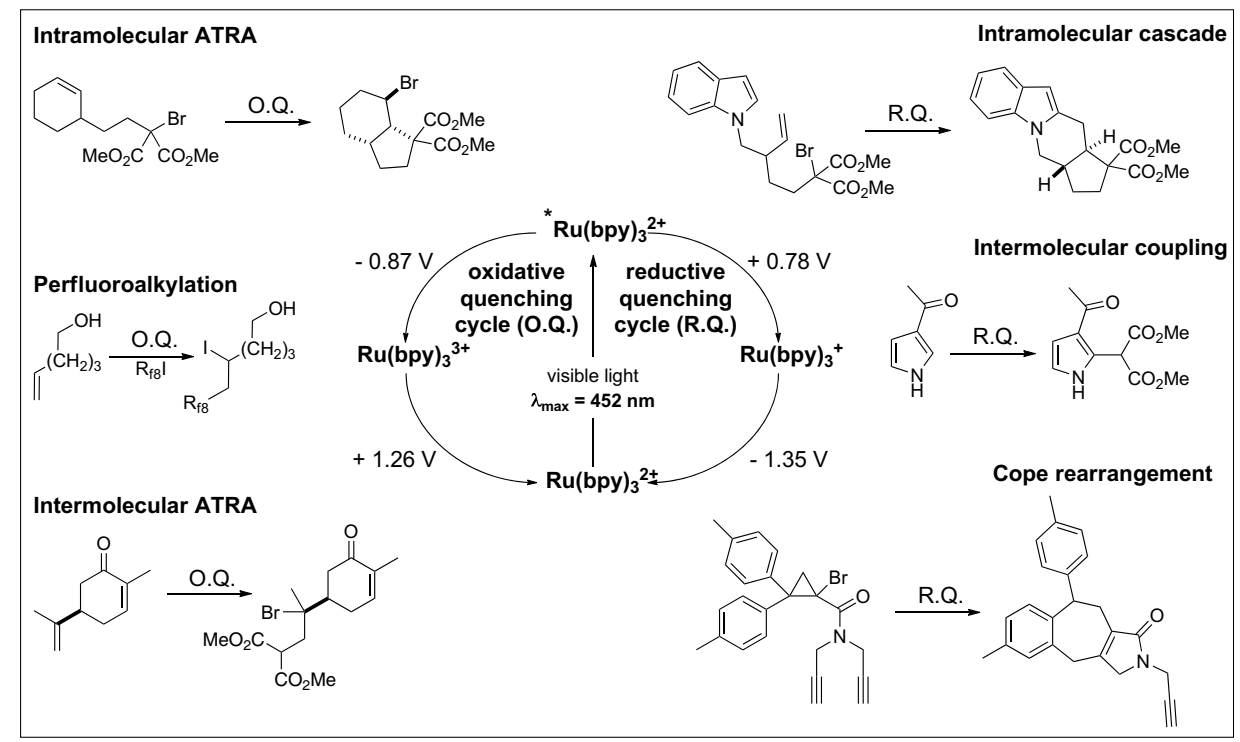

Fig. 1. Carbon-carbon bond forming reactions utilizing the oxidative and reductive quenching of photocatalysts developed in the Stephenson group. 
sign. Thus, when $\left[\mathrm{Ru}(\mathrm{bpy})_{3}\right]^{2+}$ is irradiated in the presence of an appropriate electron donor, the catalyst progresses through the reductive quenching pathway, to produce a strongly reducing species $\left[\mathrm{Ru}(\mathrm{bpy})_{3}\right]^{+}$ $(\mathrm{Ru}(\mathrm{II}) / \mathrm{Ru}(\mathrm{I})=-1.35 \mathrm{~V} \text { vs } \mathrm{SCE})^{[9]}$, which has the ability to reduce activated carbonhalogen bonds and form the corresponding carbon-centered radicals. However, in presence of an electron acceptor, a strongly oxidizing $\left[\mathrm{Ru}(\mathrm{bpy})_{3}\right]^{3+}$ species (Ru(III)/ $\mathrm{Ru}(\mathrm{II})=+1.26 \mathrm{~V}$ vs SCE$)^{[9]}$ is formed upon oxidation of $*\left[\mathrm{Ru}(\mathrm{bpy})_{3}\right]^{2+}$. The following sections describe how the redox duality of photocatalysts $\left[\mathrm{Ru}(\mathrm{bpy})_{3}\right]^{2+}, \quad\left[\operatorname{Ir}\left\{\mathrm{dF}\left(\mathrm{CF}_{3}\right)\right.\right.$ $\left.\mathrm{ppy}_{2}(\mathrm{dtbpy})\right]^{+}$and $\left[\operatorname{Ir}(\mathrm{ppy})_{2}(\mathrm{dtbpy})\right]^{+}$have been utilized in radical reductive dehalogenation, intra- and intermolecular carboncarbon bond formations, atom transfer radical additions (ATRA), construction of Cope rearrangements precursors, and iminium formation for intermolecular coupling reactions. ${ }^{[10]}$

\section{Tin-free Reductive Dehalogenation: An Entry to Free Radicals and thus C-C Bond Formation}

During the synthetic pursuit of highly functionalized pyrroloindoline scaffolds, a photocatalytic approach was developed to generate carbon-centered radicals from bromopyrrolindolines. This approach utilized $\left[\mathrm{Ru}(\mathrm{bpy})_{3}\right] \mathrm{Cl}_{2}$ and was illustrated by the reductive dehalogenation of bromopyrrolindolines to pyrrolindoline derivatives via the generation of the corresponding carbon-centered radical followed by $\mathrm{H}$-atom abstraction. ${ }^{[6 a]}$ During this investigation, activated benzylic halogens and $\alpha$-halocarbonyls efficiently underwent reduction, providing the corresponding reduced product in high to excellent yields within a time frame of 4-24 h (Scheme 1). Utilizing the reductive quenching pathway of $\left[\mathrm{Ru}(\mathrm{bpy})_{3}\right] \mathrm{Cl}_{2}$ and an equimolar combination of $i \mathrm{Pr}_{2} \mathrm{NEt}$ and Hantzsch ester or $i \mathrm{Pr}_{2} \mathrm{NEt}$ and formic acid as stoichiometric electron donor/H-atom donor combinations was pivotal for high conversions.

The successful development of a radical reductive dehalogenation utilizing $\left[\mathrm{Ru}(\mathrm{bpy})_{3}\right] \mathrm{Cl}_{2}$ prompted further investigation of the employment of photoredoxgenerated carbon-centered radicals for reductive cyclization and intermolecular coupling. $\left[\mathrm{Ru}(\mathrm{bpy})_{3}\right] \mathrm{Cl}_{2}$ was utilized to perform efficient 5-exo-trig, 6-exo-trig and 5 -exo-dig cyclizations of $\alpha$-bromo imides and bromomalonates (Scheme 2).[6b,6d] However, when the cyclization of bromoester 1 was attempted using [Ru(bpy) $)_{3}$ ] $\mathrm{Cl}_{2}$, only starting material was recovered (Scheme 3). By utilizing a photocatalyst with a stronger reduction potential, $\left[\operatorname{Ir}(\mathrm{dtbpy})(\mathrm{ppy})_{2}\right] \mathrm{PF}_{6}(\operatorname{Ir}(\mathrm{II}) / \operatorname{Ir}(\mathrm{III})=-1.51$

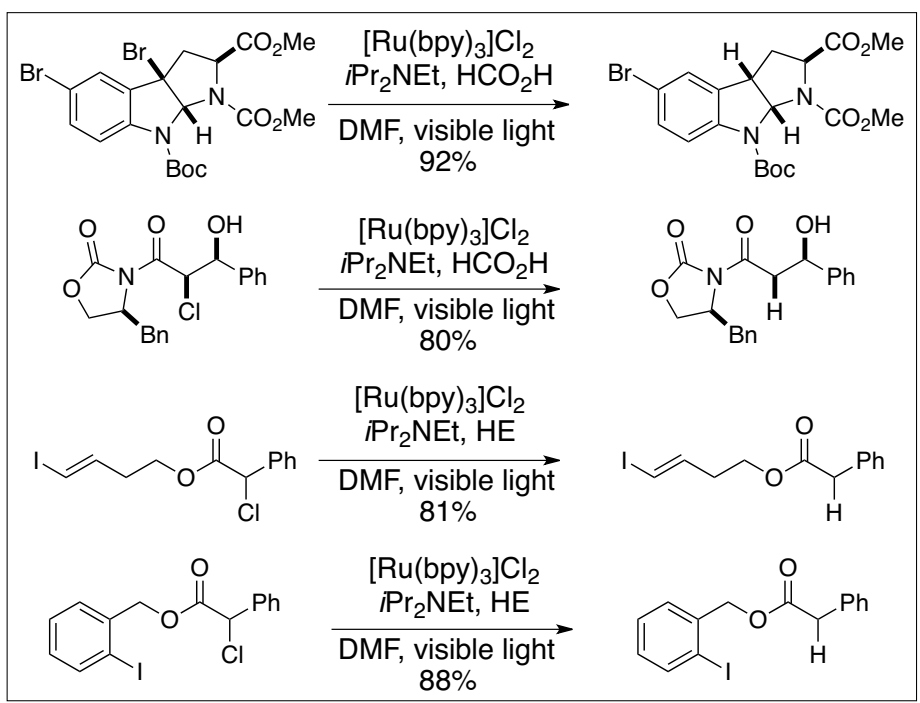

Scheme 1. Reduction of carbon-centered radicals.

V vs SCE), ${ }^{[11]}$ reductive cyclization of $\mathbf{1}$ to provide $\mathbf{2}$ proceeded in high yield. In addition, a series of $\alpha$-bromo esters, dibromocyclopropanes, and $\alpha$-bromocyclopropyl amides cyclized efficiently under irradiation in the presence of [ $\left.\operatorname{Ir}(\mathrm{dtbpy})(\mathrm{ppy})_{2}\right] \mathrm{PF}_{6}$ (Scheme 4). ${ }^{6 \mathrm{~d}]}$

When subjecting geminal diaryl functionalized N-(propynyl)cyclopropanecarboxamide derivatives to the conditions employed for reductive cyclizations, a divinyl-type rearrangement unexpectedly took place providing tricyclic pyrrolidinones. The reaction was shown to be gen-

eral for electron-rich and electron-deficient geminal and vicinal arylated cyclopropane derivatives to afford the corresponding products in high to excellent yield within a time frame of $4-12 \mathrm{~h}$ (Scheme 5A). Furthermore, the rich chemistry of halogenated cyclopropanecarboxamide derivatives was exploited as a platform for molecular diversity and reaction discovery giving access to various cyclized, electrocyclic ring-opened and reduced products. ${ }^{[6 i]}$

The optimized conditions utilized for intramolecular cyclization were applied

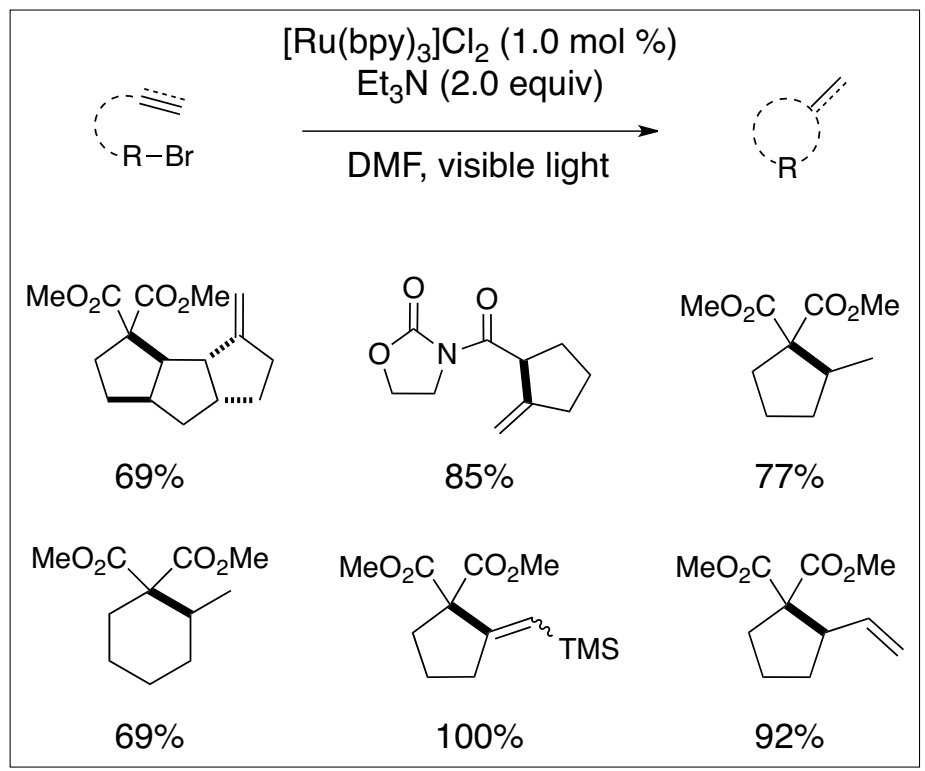

Scheme 2. Reductive radical cyclizations utilizing $\left[\mathrm{Ru}(\mathrm{bpy})_{3}\right] \mathrm{Cl}_{2}$.

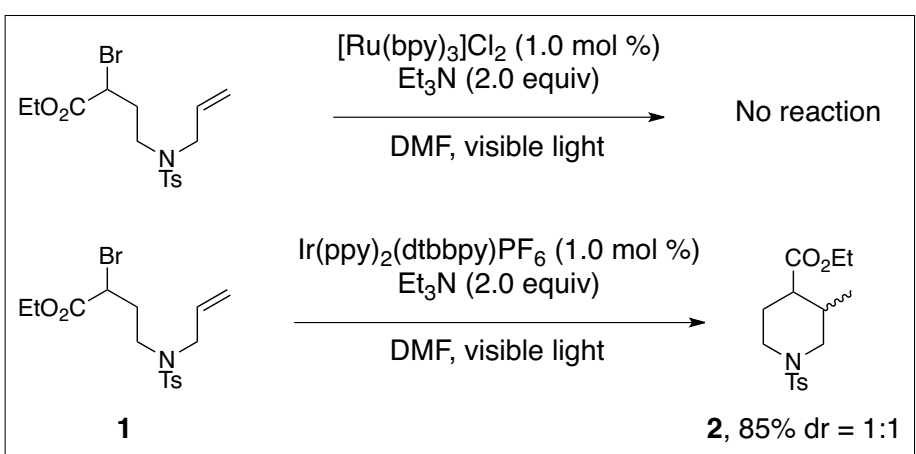

Scheme 3. Example illustrating [Ir(dtbpy) (ppy) ${ }_{2} \mathrm{PF}_{6}$ as a stronger reductant than $\left[\mathrm{Ru}(\mathrm{bpy})_{3}\right]_{2} \mathrm{Cl}_{2}$. 


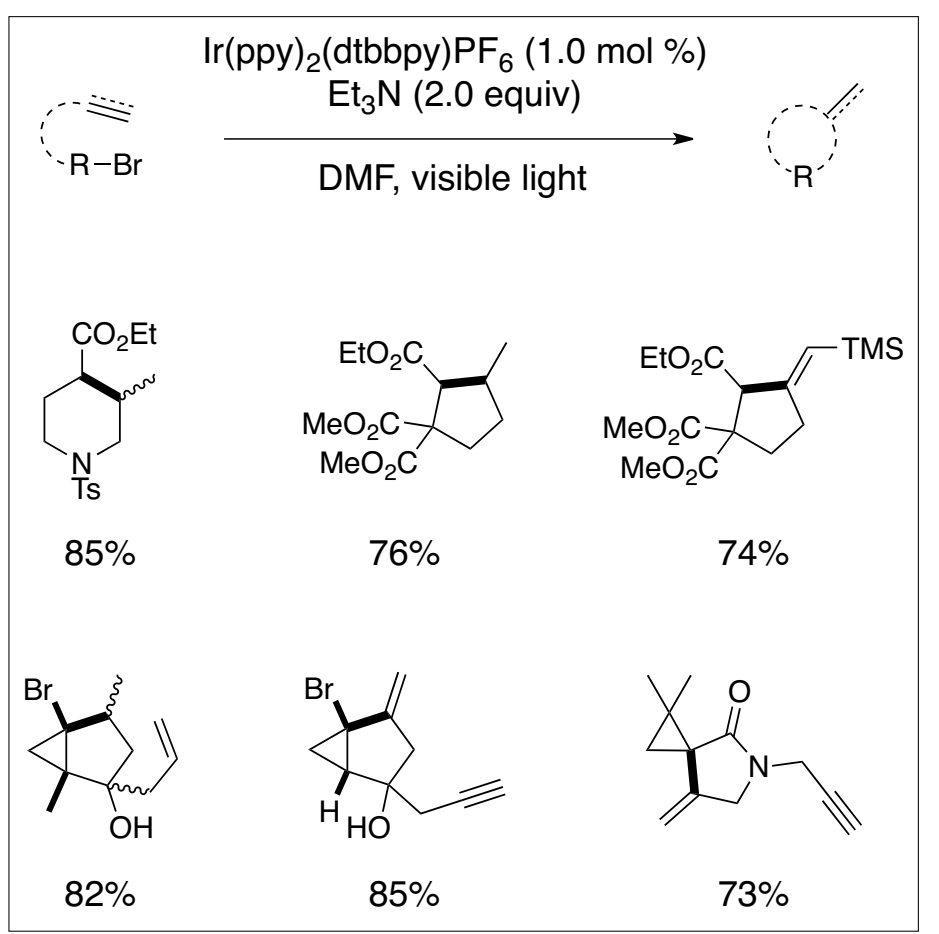

Scheme 4. Reductive radical cyclizations utilizing $[\operatorname{lr}(\mathrm{dtbpy})$ (ppy) $\left.{ }_{2}\right] \mathrm{PF}_{6}$. to the intermolecular coupling of diethylbromomalonate and $N$-methylindole. The desired product was isolated in low yield, and the major product was the reduction of diethylbromomalonate to diethylmalonate. By utilizing trialkylamines to reductively quench $\left[\mathrm{Ru}(\mathrm{bpy})_{3}\right] \mathrm{Cl}_{2}$, ammoniumyl radical ions are produced which serve as very efficient $\mathrm{H}$-atom donors (see Scheme 8 below). The replacement of triethylamine with $4-\mathrm{MeO}-\mathrm{C}_{6} \mathrm{H}_{4}-\mathrm{NPh}_{2}$ was postulated as a method to avoid the issue of premature reduction of the diethylmalonyl radical. This triarylamine would serve solely as an electron donor because it lacks $\alpha$-hydrogens to donate any $\mathrm{H}$-atoms before or after oxidation. This strategic replacement proved to be successful and the coupling of indoles, pyrroles, and furans with the dimethylmalonyl radical proceeded with moderate to high yields (Scheme 5B).

The initial coupling conditions were employed in the first scalable synthesis of (+)-gliocladin C, a member of the hexahydropyrroloindoline alkaloid family.[12] In addition to the highly efficient synthesis of

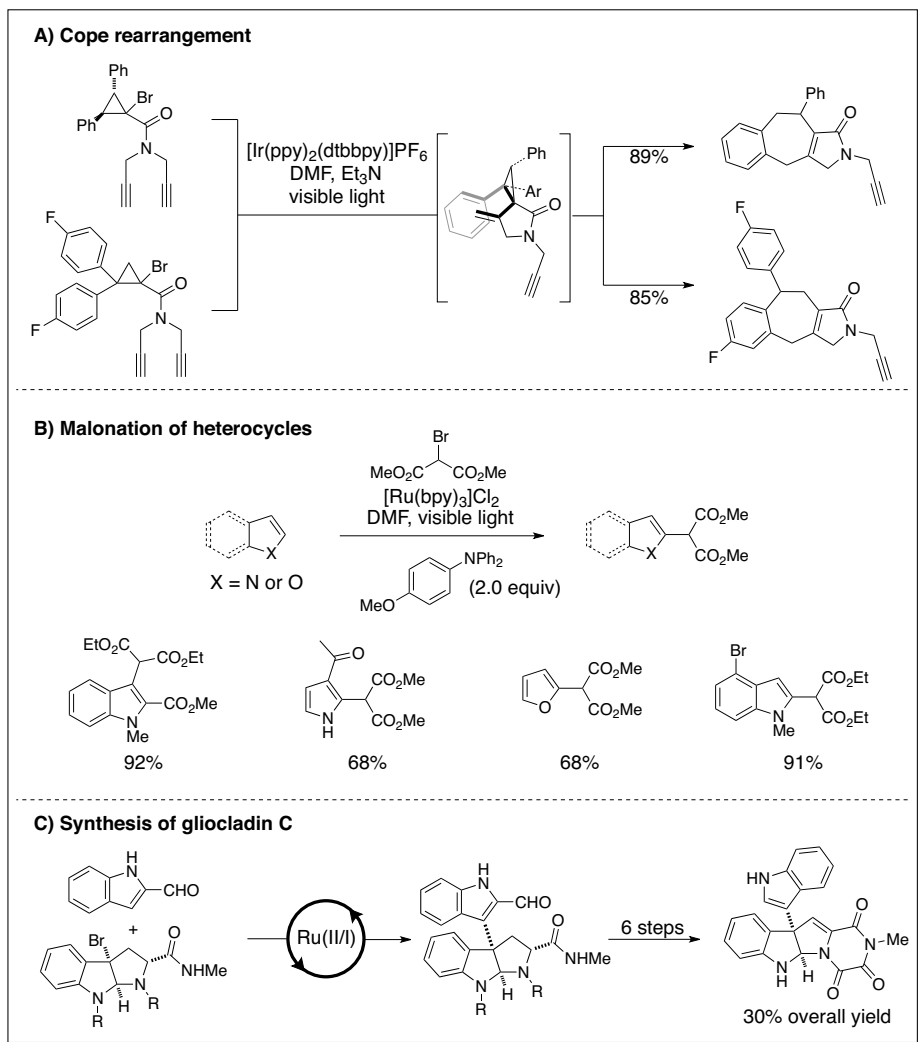

Scheme 5. Functionalization and synthesis of heterocyclic compounds. the natural product in $30 \%$ overall yield, the synthetic procedure also illustrated the first example of the employment of photoredox catalysis toward the total synthesis of a complex natural product. The key step of the synthesis utilized the reductive quenching of $\left[\mathrm{Ru}(\mathrm{bpy})_{3}\right]^{2+}$ to install the $\mathrm{C}(3)-\mathrm{C}(3)$ ' connectivity through formation of a carbon-centered radical from a bromopyrrolindoline derivative in the presence of an indole derivative, providing the coupling product in $82 \%$ yield. An additional six consecutive steps gave (+)-gliocladin C (Scheme 5C).

\section{Atom Transfer Radical Addition}

During the investigation of radical cyclizations of electron deficient radicals onto $\pi$-systems utilizing the reductive quenching of $\left[\mathrm{Ru}(\mathrm{bpy})_{3}\right] \mathrm{Cl}_{2}$ and [ $\left.\operatorname{Ir}(\mathrm{dtbbpy})(\mathrm{ppy})_{2}\right]$ $\mathrm{PF}_{6}$, atom transfer radical addition products for substrate $\mathbf{3}$ and $\mathbf{5}$ were observed. Exclusive formation of the atom transfer product of $\mathbf{5}$ was unsuccessful in the presence of a trialkylamine electron donor; however, by replacing $\left[\mathrm{Ru}(\mathrm{bpy})_{3}\right] \mathrm{Cl}_{2}$ with $\left[\operatorname{Ir}\left\{\mathrm{dF}\left(\mathrm{CF}_{3}\right) \text { ppy }\right\}_{2}(\mathrm{dtbbpy})\right] \mathrm{PF}_{6}$ and performing the reaction in the absence of an external electron donor, the exclusive formation of the ATRA product was observed (Scheme 6). While the reductive quenching of $\left[\mathrm{Ru}(\mathrm{bpy})_{3}\right] \mathrm{Cl}_{2}$ utilizes an external electron donor to generate a strong reductant $(\mathrm{Ru}(\mathrm{I}))$ the excited state of $\left[\operatorname{Ir}\left\{\mathrm{dF}\left(\mathrm{CF}_{3}\right)\right.\right.$ ppy $\left.\}_{2}(\mathrm{dtbbpy})\right] \mathrm{PF}_{6}$ is strong enough to reduce the carbon-halogen bond directly. Thus, by utilizing the oxidative quenching of $\left[\operatorname{Ir}\left\{\mathrm{dF}\left(\mathrm{CF}_{3}\right) \text { ppy }\right\}_{2}(\mathrm{dtbbpy})\right] \mathrm{PF}_{6}$, the presence of a sacrificial electron donor is no longer required, and premature reduction of the radical is no longer an issue. Optimization of the reaction conditions involved modifying the solvent system from anhydrous DMF to $4: 1 \mathrm{H}_{2} \mathrm{O} / \mathrm{DMF}$ and the addition of LiBr. Presumably, the presence of water assists the ATRA process via the hydrophobic effect, while the presence of $\mathrm{LiBr}$ provides a 'salting out' effect, ${ }^{[13]}$ in addition to promoting the reduction of $\alpha$-halocarbonyls through Lewis acid coordination. Initially, it was assumed that $\mathrm{LiBr}$ could also serve as a source of bromide to promote product formation via the nucleophlic trapping mechanism (vide infra), but the replacement of $\mathrm{LiBr}$ with other lithiated Lewis acids, such as $\mathrm{LiCl}$ and $\mathrm{LiBF}_{4}$, did not change the reaction time or yield, indicating that the major source of transferred bromide originates from the bromomalonate moiety.

The optimized conditions for the cyclization ATRA of substrate $\mathbf{5}$ were applied to intermolecular ATRA reactions between a variety of halogenated compounds and olefins to provide ATRA products in 


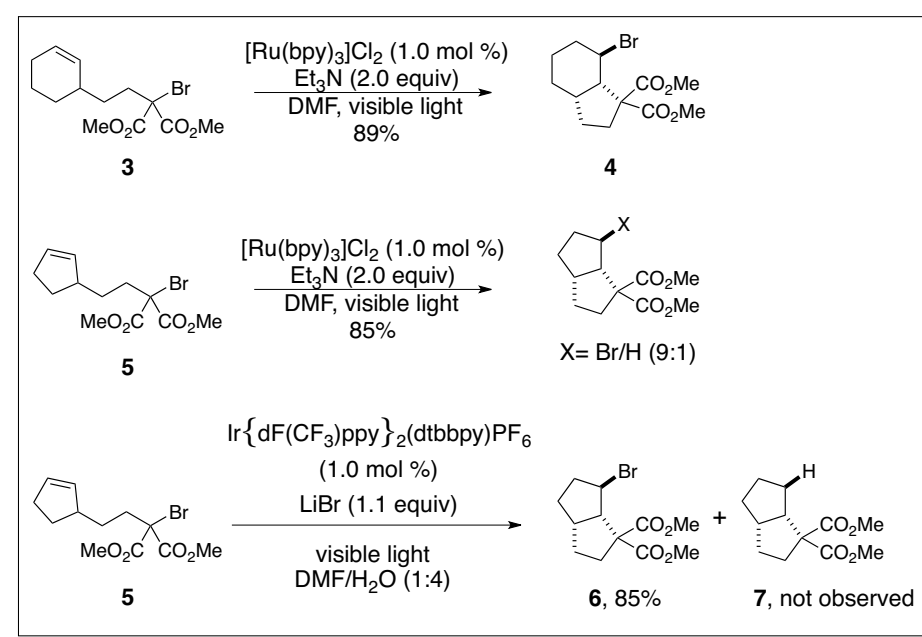

Scheme 6. Development of intramolecular atom transfer radical addition.

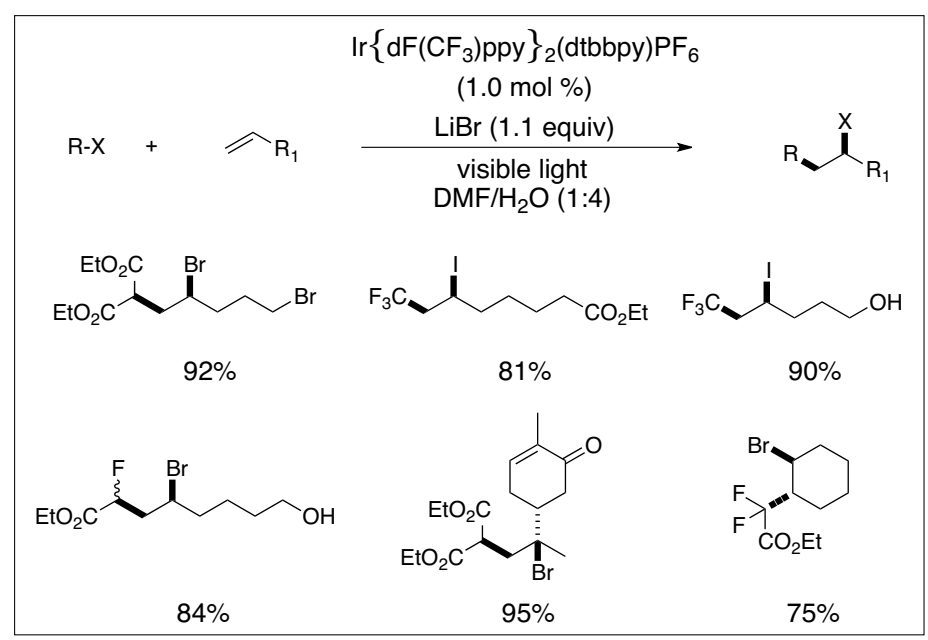

Scheme 7. Intermolecular atom transfer radical addition via oxidative quenching of $\left[\operatorname{Ir}\left\{\mathrm{dF}\left(\mathrm{CF}_{3}\right) \mathrm{ppy}\right\}_{2}(\mathrm{dtbbpy})\right] \mathrm{PF}_{6}$. good to high yields. Polyhalomethanes and $\alpha$-halocarbonyls were excellent atom transfer agents for terminal and 1,1-disubstituted olefins (Scheme 7). ${ }^{6 \mathrm{gg}]}$ However, the methodology was not without limitations. Certain halogenated compounds with reduction potentials less negative than that of the * $\operatorname{Ir}(\mathrm{III}) / \operatorname{Ir}(\mathrm{IV})$ couple $(-0.89$ $\mathrm{V}$ vs SCE), ${ }^{[11]}$ such as carbon tetrachloride and ethyl bromoacetate, did not provide the corresponding ATRA products. On the other hand, $\mathrm{CF}_{3} \mathrm{I}$, which has a reduction potential of $-1.52 \mathrm{~V}$ vs SCE,[14] did perform the atom transfer onto olefins, albeit requiring a large excess of $\mathrm{CF}_{3} \mathrm{I}$ and longer reaction times. In addition, electrondeficient olefins, styrene derivatives, and alkynes did not provide the desired atom transfer products efficiently.

The proposed mechanism of ATRA utilizing visible light active photocatalysts involves two convergent pathways that both take advantage of the oxidative quenching of $\left[\operatorname{Ir}\left\{\mathrm{dF}\left(\mathrm{CF}_{3}\right) \text { ppy }\right\}_{2}(\mathrm{dtbbpy})\right] \mathrm{PF}$. The first pathway utilizes the visible light active complex as an initiator, and the reaction is sustained by propagation. The second pathway involves a radical-polar crossover mechanism as outlined in Scheme 8. The excited state of the catalyst is initially oxidized to reduce the carbon-halogen bond. Subsequently, the oxidized ground state of $\operatorname{Ir}\left\{\mathrm{dF}\left(\mathrm{CF}_{3}\right) \text { ppy }\right\}_{2}$ (dtbbpy) $] \mathrm{PF}_{6}$ an $\operatorname{Ir}(\mathrm{IV})$ species, is reduced by the alkyl radical which provides the carbocation and regenerates the catalyst. It is most likely that the actual reaction mechanism involves both propagation and photocatalysis in which short chain propagation is coupled with the ability of the catalyst to regenerate and initiate new chains.

\section{Photocatalytic Iminium Formation}

During the development of the intraand intermolecular coupling protocols ( $v i$ de supra), it was realized that the iminium ion side product formed upon oxidation of the stoichiometric amine electron donor could potentially be trapped with various nucleophiles. In this regard, functionalization of tertiary imines could be realized photocatalytically.[6c,6j] Initial studies resulted in a procedure utilizing the ability of $\left[\operatorname{Ir}(\mathrm{ppy})_{2}(\mathrm{dtbpy})\right]^{+}$to oxidize tertiary amines to ammoniumyl radical cations under visible light irradiation. Presumably, the mechanism proceeds by electron donation from the catalyst to adventitious molecular oxygen. This electron transfer event closes the catalytic cycle and produces the radical anion of molecular oxygen, which can abstract hydrogen from

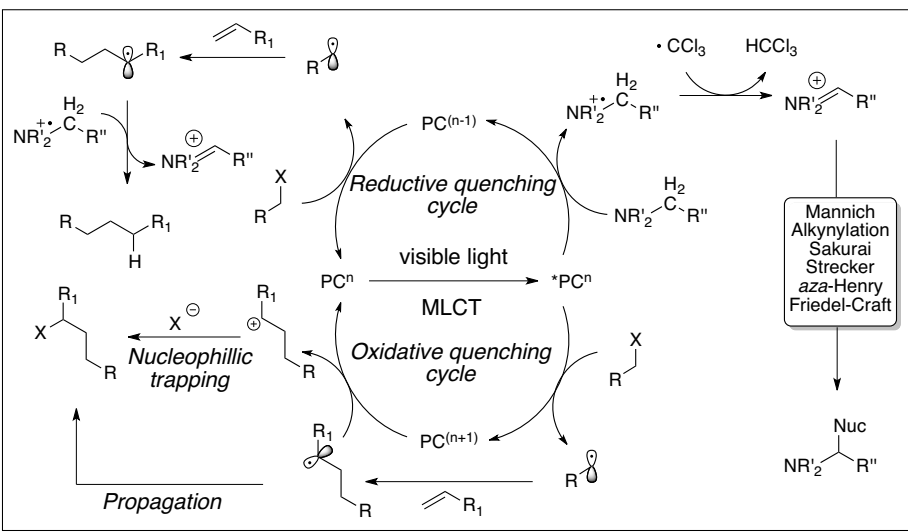

the ammoniumyl radical cation to provide the iminum ion. When subjecting tetrahydroisoquinoline derivatives to these conditions, using nitromethane as solvent, the corresponding iminium ion was successfully trapped by the solvent to provide the corresponding aza-Henry product in $92 \%$ yield. Both electron-rich and electron-deficient tetrahydroisoquinoline derivatives afforded excellent yields. Further development utilized $\left[\mathrm{Ru}(\mathrm{bpy})_{3}\right]^{2+}$ as the catalyst and $\mathrm{BrCCl}_{3}$ as stoichiometric electron- and hydrogen acceptor. The latter conditions extended the scope to allow for Streckertype functionalization, $\mathrm{Cu}$-alkynylations, Sakurai allylation, Friedel-Crafts and Mannich reactions (Scheme 9).

\section{Simplistic Implementation of Flow Techniques to Photoredox Catalysis}

Common laboratory setups using batch reactor techniques present photoredox catalysis with limitations related to inefficient light irradiation of the reaction mixture. This issue was successfully addressed by adopting common flow reactor techniques to various photoredox catalytic transformations developed by the Stephenson group (Scheme 10). ${ }^{[15]}$ A very simplistic apparatus was assembled using PFA tubing, blue LEDs as a light source and a normal peristaltic pump to pump the reaction mixture through the irradiated tubing at suitable flow rates. Initial evaluation of the reactor setup was focused on photoredox-mediated formation of iminium ions via oxidation of $N$-phenyl tetrahydroisoquinoline (vide supra) with subsequent trapping using various nucleophiles. Using $\mathrm{BrCCl}_{3}$ as a stoichiometric oxidant and $\left[\mathrm{Ru}(\mathrm{bpy})_{3}\right] \mathrm{Cl}_{2}$ as photoredox catalyst, only a residence time of $30 \mathrm{~s}$ was required to completely oxidize the tetrahydroisoquinoline starting material. The iminium 


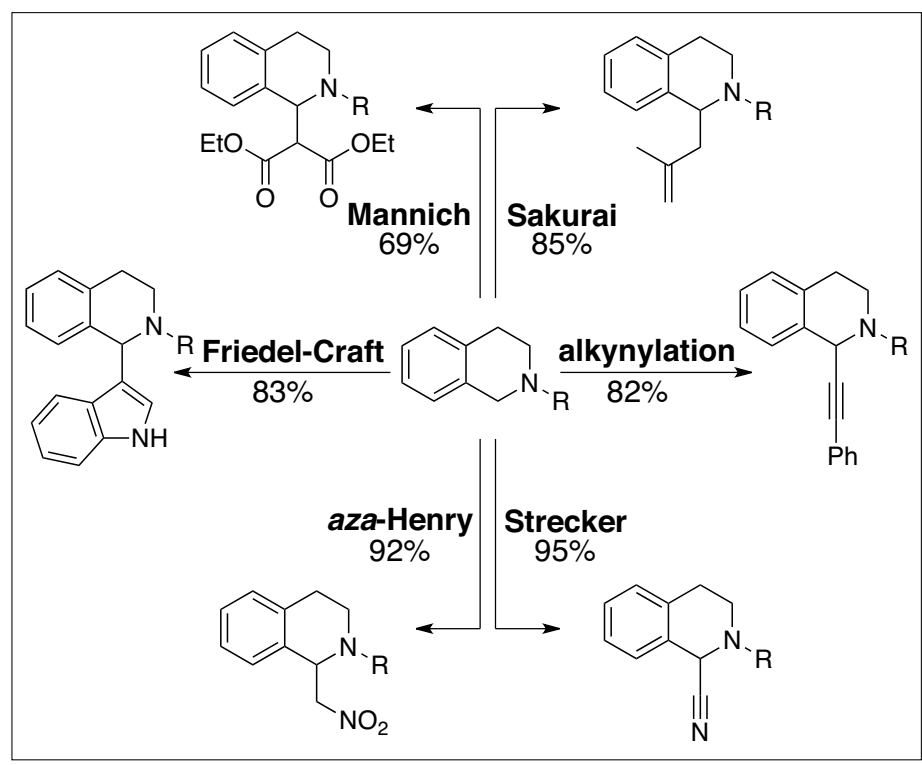

Scheme 9. $\alpha$-Carboncarbon formations with tetrahydroisoquinolines. ion was then collected in a flask containing the nucleophile of choice, providing the $\alpha$-functionalized amine in yields comparable to that of the corresponding batch reaction. For example, treating the iminium ion with a combination of nitromethane and $\mathrm{Et}_{3} \mathrm{~N}$ provided the aza-Henry product in $89 \%$ yield. This corresponds to a $7000 \%$ increase of material throughput as compared to the reaction in batch. ${ }^{[16]}$ Several types of transformations including intra- and intermolecular cyclizations and tandem radical cyclization/Cope rearrangement sequences were successfully performed in yields comparable or higher than those obtained in batch. For all examples, residence times never exceeded 10 min, providing conditions for convenient scale-up of products to gram quantities.

\section{Conclusion}

Photocatalytic transformations utilizing transition metal polypyridyl complexes have been shown to efficiently mediate carbon-carbon bond forming transformations. The reductive quenching pathway of various photocatalysts allows for both inter- and intramolecular reductive cycliza-

tions to be achieved, along with chemoselective reduction of alkyl bromides and chlorides. The oxidative quenching cycle gives access to ATRA-type reactivity of $\alpha$-bromocarbonyl compounds and polyhaloalkanes in overall redox neutral transformations. The complementary nature of the reductive and oxidative quenching pathways can be exploited to conveniently tune the reaction pathway and product outcome for various photocatalytic systems. The ability to strategically take advantage of this duality in combination with substrates that display a diverse set of reactivity allows for molecular diversity discovery, as well as method development. Furthermore, carbon-carbon bond formations are just one of several types of transformations that photocatalysis has been shown to efficiently mediate. Among others, $\mathrm{C}-\mathrm{H}$ bond activation ${ }^{[6 \mathrm{c}, 6 \mathrm{~h}, 6 \mathrm{j}]}$ and $\mathrm{C}-\mathrm{O}$ bond activation $^{[6 f]}$ have also successfully been accomplished via photoredox catalysis. Due to the interesting characteristics and mild reaction conditions photocatalysis provides, we can expect new methods and new approaches to old synthetic difficulties to emerge in the upcoming literature.

Received: March 10, 2012

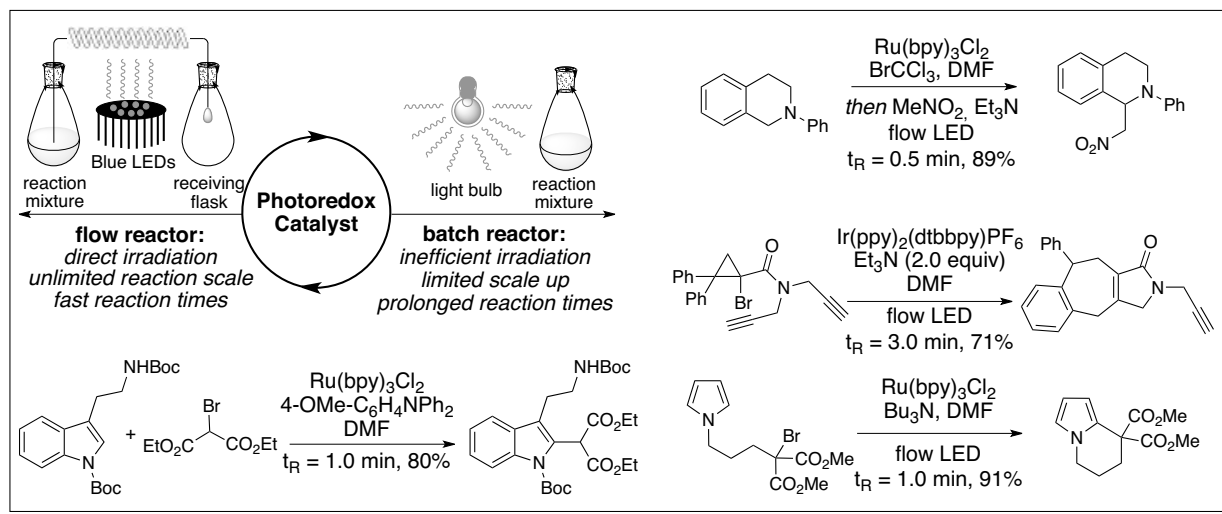

Scheme 10. Combining photoredox catalysis with flow techniques.
[1] A. Albini, M. Fagnoni in 'Handbook of Synthetic Photochemistry', Ed. A. Albini, M. Fagnoni, WILEY-VCH Verlag GmbH \& Co. $\mathrm{KGaA}$, Weinheim, 2010.

[2] a) D. M. Hedstrand, W. H. Kruizinga, R. M Kellogg, Tetrahedron Lett. 1978, 14, 1255; b) S. H. Mashraqui, R. M. Kellogg, Tetrahedron Lett. 1985, 26, 1453; c) T. J. van Bergen, D. M Hedstrand, W. H. Kruizinga, R. H. Kellogg, J. Org. Chem. 1979, 26, 4953.

[3] a) J.-M. Kern, J.-P. Sauvage, J. Chem. Soc., Chem. Commun. 1987, 8, 546; b) K. Hironaka, S. Fukuzumi, T. Tanaka, J. Chem. Soc., Perkin Trans. 2 1984, 10, 1705.

[4] For selected examples see: a) P. V. Pham, D. A. Nagib, D. W. C. MacMillan, Angew. Chem., Int Ed. 2011, 50, 6119; b) D. A. Nagib, D. W. C. MacMillan, Nature 2011, 480, 224.

[5] For selected examples see: a) J. Du, L. Ruiz Espelt, I. A. Guzei, T. P. Yoon, Chem. Sci. 2011, 2, 2115; b) Z. Lu, M. Shen, T. P. Yoon, J. Am. Chem. Soc. 2011, 133, 1162.

[6] a) J. M. R. Narayanam, J. W. Tucker, C. R. J. Stephenson, J. Am. Chem. Soc. 2009, 131, 8756 ; b) J. W. Tucker, J. M. R. Narayanam, S. W. Krabbe, C. R. J. Stephenson, Org. Lett. 2010, 12, 368; c) A. G. Condie, J.-C. González-Gómez, C. R. J. Stephenson, J. Am. Chem. Soc. 2010, 132, 1464; d) J. W. Tucker, J. D. Nguyen, J. M. R. Narayanam, S. W. Krabbe, C. R. J. Stephenson, Chem. Commun. 2010, 46, 4985; e) L. Furst, B. S Matsuura, J. M. R. Narayanam, J. W. Tucker, C. R. J. Stephenson, Org. Lett. 2010, 12, 3104; f) C. Dai, J. M. R. Narayanam, C. R. J. Stephenson, Nature Chem. 2011, 3, 140; g) J. D. Nguyen, J. W. Tucker, M. D. Konieczynska, C. R. J. Stephenson, J. Am. Chem. Soc. 2011, 133, 4160; h) J. W. Tucker, J. M. R. Narayanam, P. S. Shah, C. R. J. Stephenson, Chem. Commun. 2011, 47, 5040; i) J. W. Tucker, C. R. J. Stephenson, Org. Lett. 2011, 13, 5468; j) D. B. Freeman, L. Furst, A. G. Condie, C. R. J. Stephenson, Org. Lett. 2012, 14, 94.

[7] For recent reviews on photocatalysis see: a) J. M. R. Narayanam, C. R. J. Stephenson, Chem. Soc. Rev. 2011, 40, 102; b) F. Teply, Collect. Czech. Chem. Commun. 2011, 76, 849; c) T. P. Yoon, M. A. Ischay, J. Du, Nature Chem. 2010, 2, 527; d) K. Zeitler, Angew. Chem., Int. Ed. 2009, 48,9785

[8] J. W. Tucker, C. R. J. Stephenson, J. Org. Chem. 2012, 77, 1617.

[9] A. Juris, V. Balzani, F. Barigelletti, S Campagna, P. Belser, V. Von Zelewsky, Coord. Chem. Rev. 1988, 84, 85 .

[10] For detailed mechanistic considerations, please see appropriate references as provided in conjunction with the different transformations.

[11] L. Flamigni, A. Barbieri, C. Sabatini, B. Ventura, F. Barigelletti, Top. Curr. Chem. 2007, $281,143$.

[12] L. Furst, J. M. R. Narayanam, C. R. J. Stephenson, Angew. Chem., Int. Ed. 2011, 50, 9655.

[13] H. Nambu, G. Anilkumar, M. Matsugi, Y. Kita, Tetrahedron 2003, 59, 77

[14] C. P. Andrieux, L. Gelis, M. Medebielle, J. Pinson, J. M. Saveant, J. Am. Chem. Soc. 1990, $112,3509$.

[15] J. W. Tucker, Y. Zhang, T. F. Jamison, C. R. J. Stephenson. Angew. Chem. Int. Ed. 2012, 51, 4144.

[16] For a reactor volume of $479 \mu \mathrm{L}$. 